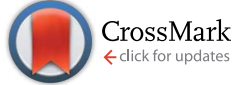

Cite this: J. Mater. Chem. C, 2014, 2 , 6637

\section{Engineering fused coumarin dyes: a molecular level understanding of aggregation quenching and tuning electroluminescence via alkyl chain substitution $\uparrow$}

\begin{abstract}
Sunil Kumar, ${ }^{a}$ Punita Singh, ${ }^{\mathrm{b}}$ Ritu Srivastava, ${ }^{\mathrm{b}}$ Rik Rani Koner, ${ }^{\mathrm{a}}$ Avijit Pramanik, ${ }^{\mathrm{c}}$ Jomon Mathew, ${ }^{d}$ Sougata Sinha, ${ }^{a}$ Madhu Rawat, ${ }^{e}$ R. S. Anand ${ }^{e}$ and Subrata Ghosh ${ }^{\star a}$

Simple molecular structures capable of emitting over the entire visible range are still a challenge. Planar molecular structures have the drawback of fluorescence quenching in the solid state thus limiting their application fields. Combining long range excimer/exciplex emissions with a compound emission have been used to get white light. In this work, a series of new coumarin derivatives having a planar structure have been synthesized and characterized. The effects of systematic variation in alkyl chain functionalization providing morphological variations that permit interesting solid state emitting properties have been discussed simultaneously with electrochemical behavior and OLED (organic light emitting diode) device applications. Carbon chains containing 0-16 carbon atoms have been studied in order to conclude the results that systematic changes in alkyl group substitution can be utilized as a tool to tune the emitting color of these planar coumarins. Alkyl chains were introduced by $\mathrm{O}$-acylation and O-benzoylation reaction on the hydroxyl group of parent coumarin 5 . Thus the present strategy is also helpful in establishing a template to control the unproductive interchromophore electronic couplings. Solid state fluorescence properties support the crystal studies. Theoretical studies are also in agreement with experimental data. Electroluminescence of Device 2 with a turn on voltage $\left(V_{\text {on }}\right)$ around 5-6 V having S-CBP doped with $1 \%$ of 8 having alkyl substitution of 2 -carbons is found to exhibit white emission with CIE co-ordinates of $(0.29,0.34)$ which is close to white emission while the alkyl substitution of 14-carbons (compound 17$)$ in Device $7\left(V_{\text {on }}=7 \mathrm{~V}\right)$ exhibited green emission. Thus a strategy helpful to tune the electroluminescence has been discussed.
\end{abstract}

Received 21st April 2014 Accepted 9th June 2014 DOI: $10.1039 / c 4 t c 00807 c$ www.rsc.org/MaterialsC are lacking in the literature and only a few reports are available. $^{3-6}$ The most commonly exploited approaches for white light emissions ${ }^{7}$ include multilayered device fabrication by consecutive evaporation of different emitting compounds, ${ }^{7-11}$ spin coating of a blend of different soluble emitters, ${ }^{12}$ utilizing excimer or exciplex emission, ${ }^{13}$ use of organic-metal complexes in a hybrid device structure ${ }^{5,14}$ and phosphorescent emitters with a suitable host. ${ }^{15}$ The device structure also plays an important role for white emission. Phosphorescent emitters have the drawback of their high cost and complicated device structures. So to be practically useful in WOLEDs, emission from a single compound is always desired for simple device fabrication. White organic light emitting diodes (WOLEDs) having a single emitting component have advantages such as reproducibility, better device stability and simple device fabrication process. $\mathrm{Kim}^{\mathbf{1 6}}$ and colleagues have recently illustrated the production of white light utilizing excited-state intramolecular proton transfer (ESIPT). In this frame, the area of synthesizing new fluorescent organic moieties showing emissions over a wide range in their solid state is still interesting and 
challenging for researchers. Coumarins have been compounds of interest for decades because of their wide range of applications in electronics and photonics due to their good stabilities and ease of synthesis and thereby finding applications as sensors ${ }^{17}$ and emitters for solid state dye lasers and OLEDs. ${ }^{18-20}$ But, due to aggregation and intermolecular interactions $(\pi-\pi$ interactions) in planar coumarin structures, they easily suffer from self-quenching, thus limiting their applicability in OLEDs. ${ }^{21}$ In this regard, the discovery of a host-guest doped emitter system has proved a boon to the emissive display technology. ${ }^{22}$ Simultaneously, work has been done to reduce aggregation $^{23} /$ dye-dye interactions ${ }^{21}$ of planar luminophores. As controlled $\pi-\pi$ interactions hold key to give origin to long range emissions (excimer/exciplex formation) and hence has been used as a boon for light generation especially white electroluminescence (EL). ${ }^{6,24}$ Therefore the design of new fluorescent materials for OLEDs as well as the development of a simple device structure has received much attention over the past decade.

It is known that simple alkyl substitutions can change the morphology of organic compounds by reducing the interluminophore alignment. Researchers have used alkyl substituents as a tool to reduce intermolecular interactions ${ }^{25}$ and modify transport properties. ${ }^{26}$ This strategy has also been used to tune the optical properties of luminophores. ${ }^{27-30}$ But a systematic study of the alkyl substitution effect on the morphology and photoluminescence properties which make the alkyl substitution effect useful in OLEDs remained mostly unexploited. In this context the search for new electroluminescent materials for white emission lead us to synthesize planar coumarin derivatives with extended $\pi$-conjugation and we wish to report a simple three-step synthesis procedure of novel coumarin dopants, PL performance with alkyl chain substitution and preliminary results on the potential utility of these compounds in a doped OLED device structure. To the best of our knowledge, this is the first attempt to explain the alkyl chain length effect on PL behavior of luminophores and it was observed that small alkyl chain substitution (compounds 8 and 11) produced white EL while longer chain substitution showed green EL for these coumarin dopants (compounds $\mathbf{1 6}$ and 17). The physical properties such as UV-vis absorption, fluorescence (both in solution and solid states), crystal structure, electrochemical behavior and thermal properties were also studied.

\section{Experimental}

\section{General information}

All the starting reactants were purchased from available commercial sources (Sigma-Aldrich, Merck and Sd-fine Chemicals) and were used as received. Spectroscopic solvents were utilized for photophysical studies. ${ }^{1} \mathrm{H}$ and ${ }^{13} \mathrm{C}$ NMR spectra were recorded using a Jeol ECX $500 \mathrm{MHz}$, Jeol ECS $400 \mathrm{MHz}$, Bruker Avance $600 \mathrm{MHz}$, Bruker AV $400 \mathrm{MHz}$ spectrometers in $\mathrm{CDCl}_{3}$ and DMSO- $d_{6}$. UV-vis and fluorescence spectra were recorded using a Shimadzu UV-2450 and Cary Eclipse fluorescence spectrophotometer (Agilent Technologies), respectively. FT-IR spectra were recorded using a Perkin Elmer Spectrum 2 spectrophotometer. Mass analysis was carried out using a micrOTOF-QII mass spectrometer. Thermal behaviour studies were done using a NETZCH STA449 F1 instrument. Melting points were recorded using a Stuart SMP30 instrument. The electrochemical cyclic voltammetry (CV) was performed using a EPSILON electrochemical workstation in $0.1 \mathrm{M}$ tetrabutylammonium hexafluorophosphate $\left(\mathrm{Bu}_{4} \mathrm{NPF}_{6}\right)$ with a scan speed at $0.1 \mathrm{Vs}-1$. A Pt wire and $\mathrm{Ag} / \mathrm{AgCl}$ were used as the counter and reference electrodes, respectively, for the CV measurements. The EL spectrum has been measured with a high resolution spectrometer (Ocean Optics HR-2000CG UV-NIR). The currentvoltage-luminescence $(I-V-L)$ characteristics have been measured with a luminance meter (LMT 1-1009) interfaced with a Keithley 2400 programmable voltage-current digital source meter.

\section{Synthesis and characterization}

The synthesis and characterization of synthesized coumarin derivatives can be found in the ESI. $\dagger$

\section{Device fabrication}

Indium-tin oxide (ITO) coated glass substrates with a sheet resistance of $20 \Omega \square^{-1}$ were used as anodes which were patterned and cleaned by a conventional solution cleaning process. The substrates were further exposed to oxygen plasma to enhance the work function. All the layers were deposited by vacuum deposition at a base pressure of $1 \times 10^{-6}$ Torr with a deposition rate of $0.1 \AA \mathrm{s}^{-1}$. The doped films were deposited by a co-evaporation process. The thicknesses of all the films were measured in situ by a quartz crystal thickness monitor. The size of each pixel was $4 \times 4 \mathrm{~mm}^{2}$. All further measurements were performed at room temperature and under an ambient atmosphere, without any encapsulation.

\section{X-ray crystallography}

Compound $\mathbf{5}$ crystallized as light brown crystals utilizing a slow crystallization method from the DMF-water mixture while compound 8 gave needle like yellow crystals in the THF solvent, which were then used for XRD analysis. X-ray crystallography data was collected using a Bruker SMART APEX CCD diffractometer. $\dagger$

\section{Results and discussion}

\section{Synthesis and characterization}

Compounds 5, 6 and 7 were synthesized, starting from aromatic aldehydes and ethyl cyanoacetate, utilizing a previously reported procedure ${ }^{31}$ and the same was followed to obtain compound 4 (Scheme 1). All products were obtained as precipitates and were obtained in pure form by simple ethanol washing avoiding a tedious and time consuming column purification technique. Further derivatization of 5, 6 and 7 was carried out utilizing triethyl amine and required acid chlorides to obtain compounds 8-21 and ethylchloroformate for 22, respectively (Scheme 1). All derivatives were obtained as a single spot on TLC 


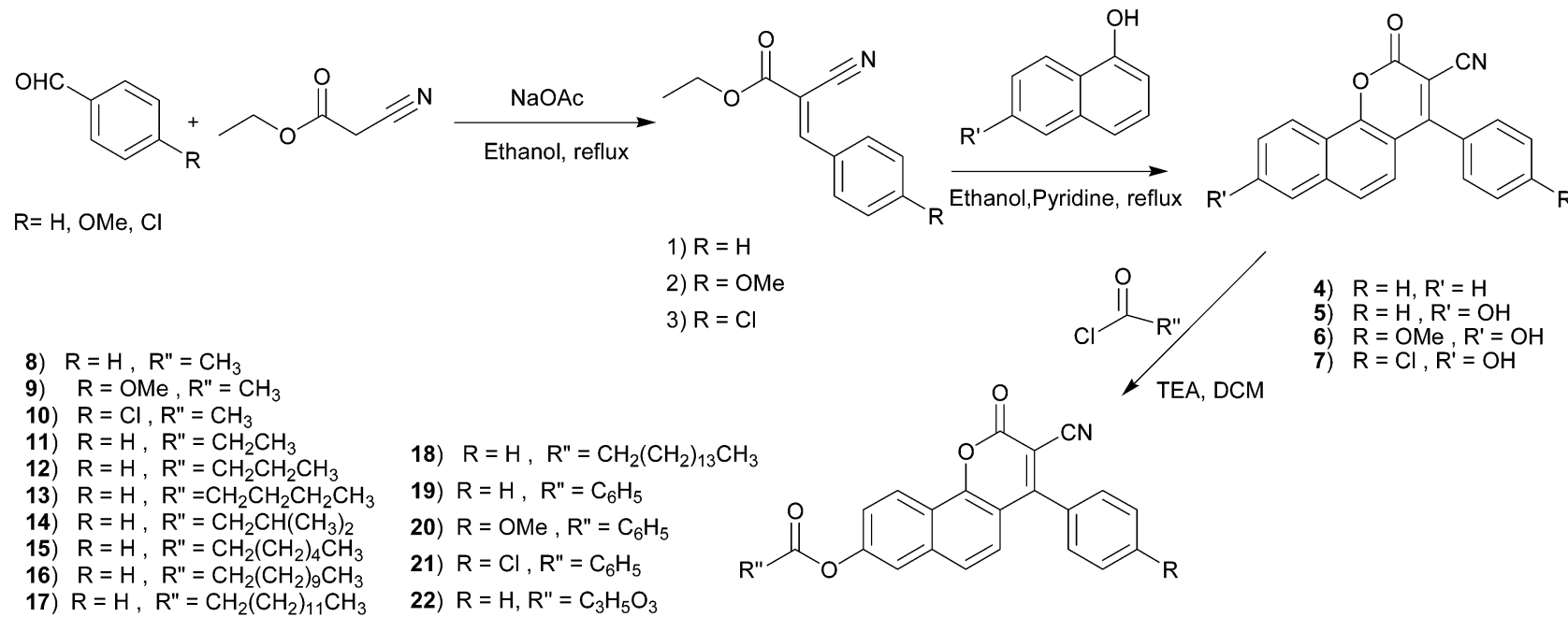

Scheme 1 Schematic representation of a three-step synthesis procedure acquired to obtain coumarin derivatives.

and further purified by water washing. The synthesized compounds were characterized by ${ }^{1} \mathrm{H} /{ }^{13} \mathrm{C}-\mathrm{NMR}$, FT-IR and mass spectroscopy. Structural identities of parent compound $\mathbf{5}$ and one of daughter compounds 8 have been investigated and authenticated by making use of single crystal X-ray crystallography.

UV-vis absorption and fluorescence spectra of all newly developed coumarins (4-22) (Scheme 1) were recorded in the
THF solvent at room temperature (Fig. 1). Absorption profiles for compounds 9, 10, 20 and 21 are shown in the ESI (Fig. S1 $\dagger$ ). All compounds showed absorbance in the region of $270-460 \mathrm{~nm}$ and an absorption profile were almost similar due to the common coumarin core. Peaks in the region of $280-340 \mathrm{~nm}$ were characteristic of a naphthalene ring and assigned to single electron $\pi-\pi^{*}$ transitions in the aromatic ring. ${ }^{32}$ Long wavelength absorption was expected due to extended $\pi$-conjugation
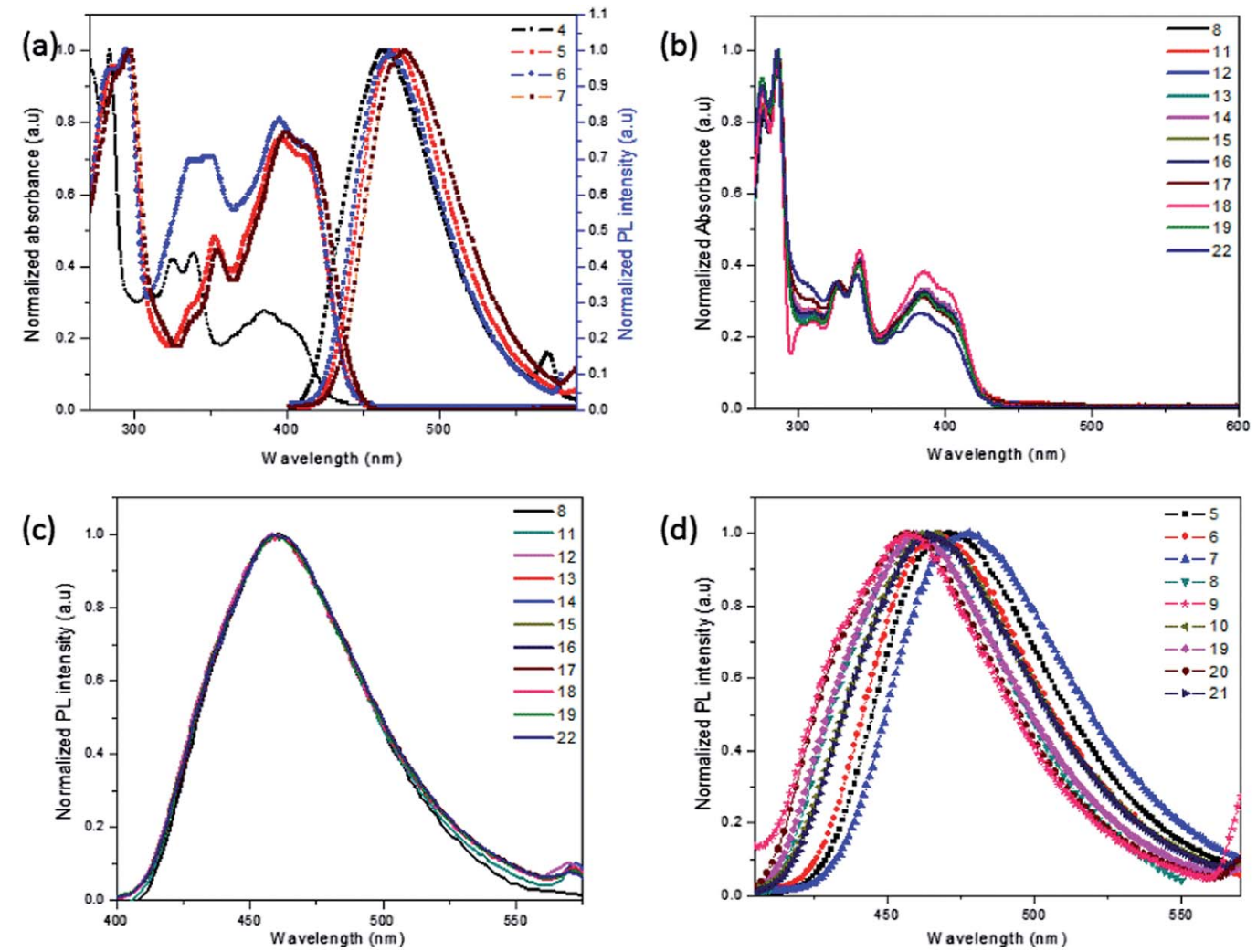

Fig. 1 (a) Normalized absorbance and PL spectra of 4, 5, 6 and 7. (b) UV spectra of compounds 8, 11-19 and 22. (c) PL spectra of compounds 8 , 11-19 and 22. (d) Comparison of PL spectra of compounds 5-10, 19-21. (All spectra were recorded in $5 \mu \mathrm{M}$ THF solution). 
of the molecule. Compound 4 showed a sharp peak at $284 \mathrm{~nm}$, multiple peaks in the region of $320-340 \mathrm{~nm}$, and a broad absorbance at around $394 \mathrm{~nm}$. The introduction of hydroxy $(-\mathrm{OH})$ functionality to 4 resulting in coumarin 5 shifted the UV-vis spectrum bathochromically as expected by 4-14 nm (Fig. 1) which could be assigned to the formation of a push-pull system $(D-\pi-A)$ due to the electron donating nature of a hydroxyl group and the electron withdrawing nature of a cyanide group. We also studied the effect of electron donor (methoxy) and electron acceptor (chloro) substitution on absorption and fluorescence properties of 5. Almost a negligible shift in the absorption spectrum was observed for $\mathbf{6}$, but a red shift of $3 \mathrm{~nm}$ was observed for 7 as compared to 5 . A reasonable explanation for this shift as compared to 4 is that a combination of a donor (hydroxy) and two acceptors (chloro and cyano) contributes to a good intramolecular charge transfer (ICT) process in 7 . To confirm the existence of a D- $\pi-\mathrm{A}$ system in these coumarin derivatives, we converted a donor group $(-\mathrm{OH})$ into an acceptor by ester (8-21)/carbamate (22) protection. As expected a blue shift in the absorption profile was observed in 8-22 because of the reduction of electron density on the aromatic ring. These results further demonstrated that UV-vis spectra of the compound $\mathbf{4}$ depend on the substituents, for example, with the introduction of the electron donor (5-7) the spectra were found to be red shifted and, on the other hand, converting a donor into an acceptor (8-22) caused a blue shift in absorption spectra.

Similarly, upon excitation $5 \mu \mathrm{M}$ THF solution of compounds showed blue emission with an emission wavelength in the region of 461-477 $\mathrm{nm}$. Parent compound 4 showed a maximum emission at $464 \mathrm{~nm}$ with a full width at half maximum (fwhm) of $73 \mathrm{~nm}$ which was red shifted by $7 \mathrm{~nm}, 4 \mathrm{~nm}$ and $13 \mathrm{~nm}$ with a fwhm of $67 \mathrm{~nm}, 64 \mathrm{~nm}$ and $70 \mathrm{~nm}$ for the compounds 5, 6 and 7 respectively. The observed red shift was expected due to the introduction of a hydroxyl group. On conversion of the hydroxyl into an ester functionality, the compounds 8-21 showed blue shifted fluorescence as compared to parent compounds 5-7. This behavior is similar to the UV-vis data for these compounds. Compound 22 behaved similarly as ester protected compounds (8-21). Quantum yields $(\Phi)$ for compounds could be found in the ESI (Table S2 $\dagger$ ). Compound 8, 11-18 showed a quantum yield in the range of 0.03-0.08 while compound 5 showed a higher quantum yield of 0.11 . In order to study the photophysical properties of these coumarins more precisely, compounds 8-18 were selected for thin film studies. Photoluminescence (Fig. 2) experiments were carried out for their thin films prepared on a quartz plate using a spin coater. The PL of compound 8 and 11-18 showed good fluorescence in the solid state compared to compound $\mathbf{5}$. The PL spectra for $\mathbf{8}$ in the thin film showed red shifts from their PL in solution. Similar results were obtained for compounds 11-18. Such a kind of red shift in PL emission in the solid state is common and has been observed by others for organic small molecules as well as polymeric materials ${ }^{33}$ possibly due to (a) the exciton hopping process in the solid state, (b) the intermolecular interaction in the solid state i.e. adjacent molecules may come close enough to have charge transfer in the excited state which manifests as a continuum of states that disturb the vibronic pattern, leading to the observed broadening and red shifted emissions ${ }^{33}$ and (c) the change in the dielectric constant of media on going from solution to quartz can also contribute to the red shift, both in PL and absorption profiles. Of all these compounds, 8 and 11 exhibited interesting vibronically defined PL behavior in the solid state (thin film). A red shift of $35 \mathrm{~nm}$ with peak emission at $496 \mathrm{~nm}$ and a hump around $532 \mathrm{~nm}$ tailing up to $650 \mathrm{~nm}$ was observed for $\mathbf{8}$ and similar behavior was observed for compound 11. The remaining compounds (12-18) gave a broad structure with single emission profiles (Fig. 2). But when PL was recorded for powdered compound $\mathbf{8}$, interestingly the hump around $532 \mathrm{~nm}$ became pronounced (Fig. 2). These dramatic changes of PL in the solid state encouraged us to investigate the origin of a greenish yellow band. Additional broad emissions may be caused by the formation of an excimer, phosphorescence or by aggregation. Careful perusal of absorption and emission profiles of $\mathbf{8}$ in both solution and solid states helped us to conclude that the emission at $532 \mathrm{~nm}$ come into existence only in the excited state since no new absorption for this emission was detected in the thin film. So we can cast away the idea of formation of the aggregate state between solid subunits as the source of the additional peak in the emission profile. Moreover, the experimental results validate that an efficient excimer formation process may occur in the molecular aggregate leading to an additional emission band in luminescence and here this process existed efficiently in powder form. ${ }^{34}$

Compound 11 showed a similar type of behavior in powder form (Fig. S2 $\dagger$ ), but as the chain length of ester protection increased from 4-carbon to 16-carbon atoms (compounds 12-18), it seemed that the excimer formation process was slaked and structure less emissions were observed as these chains might not let molecules come close enough to interact with each other which disfavored the formation of new emissions. Moreover long chain substitution plays a different role in molecular packing in aggregate form because they are known to increase the intermolecular distance between neighboring molecules which can reduce ACQ (aggregation caused quenching). But they can also induce disorder in molecular arrangement and reduce the emission process. Therefore the optimized size of an alkyl side chain for better emission in the solid state is difficult to get theoretically. In our case we got maximum fluorescence intensity for compound $\mathbf{1 7}$ having alkyl substitution of 14-carbons while a decrease in fluorescence intensity was observed for alkyl substitution of 16-carbons (Fig. S2 $\dagger$ ). It is known that introduction of donor and/or acceptor groups into a fluorogen not only give an ICT (intramolecular charge transfer) property but typically also lead to a strong solvatochromic effect ${ }^{35}$ and thus the behavior of fluorescence and absorbance as a function of solvent polarity was studied. As anticipated, fluorescence experiment data indicated that these coumarin derivatives exhibit little solvatochromic behaviour. As shown in Fig. 3, changing the solvent system from DCM to DMSO was accompanied by a small bathochromic shift of $14 \mathrm{~nm}$ in the emission wavelength $\left(\lambda_{\mathrm{em}}\right)$ of $\mathbf{8}$. Compound 4 also showed a positive solvatochromism employing a shift of $18 \mathrm{~nm}$ in $\lambda_{\mathrm{em}}$ from $464 \mathrm{~nm}$ (DCM) to $482 \mathrm{~nm}$ (DMSO). 

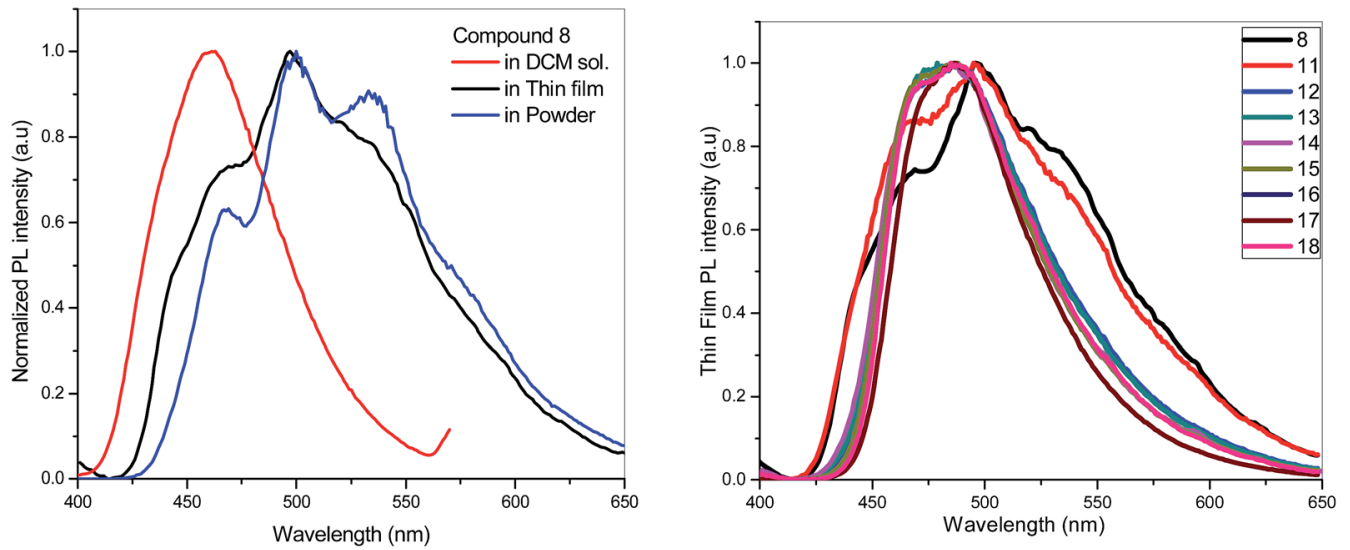

Fig. 2 (a) Comparison of shifts in the emission profile for compound 8 in dichloromethane solution, thin film and powder form and (b) comparison of thin film emission profiles for compounds 8 and 11-18.

Compounds 5, 6 (Fig. 3) and 7 (Fig. S3†) exhibited fluorescence emission wavelength shifts of $36 \mathrm{~nm}, 29 \mathrm{~nm}$ and $39 \mathrm{~nm}$, respectively, indicating 7 to be an efficient solvatochromic compound. Compounds 9-22 also showed positive solvatochromic behavior as emission wavelengths were found to be red shifted with increase in solvent polarity (Fig. S3-S9†). But an almost negligible effect on the absorption profile (Fig. S10 and $\mathrm{S} 11 \dagger$ ) was observed for all these compounds. This suggested that a dipole moment in the ground state was not much affected by solvent polarity, ${ }^{36}$ while the red shift in fluorescence $^{37}$ emission is more likely due to the absorption occurring to a locally excited state which then interconverts into a charge-transfer state prior to emission.

Compounds 5, 8, 11 and 12 were selected to study typical AEE characteristic where they ensued the formation of aggregates. ${ }^{38}$ As the water content was increased from $0 \%$ to $20 \%$ in THF

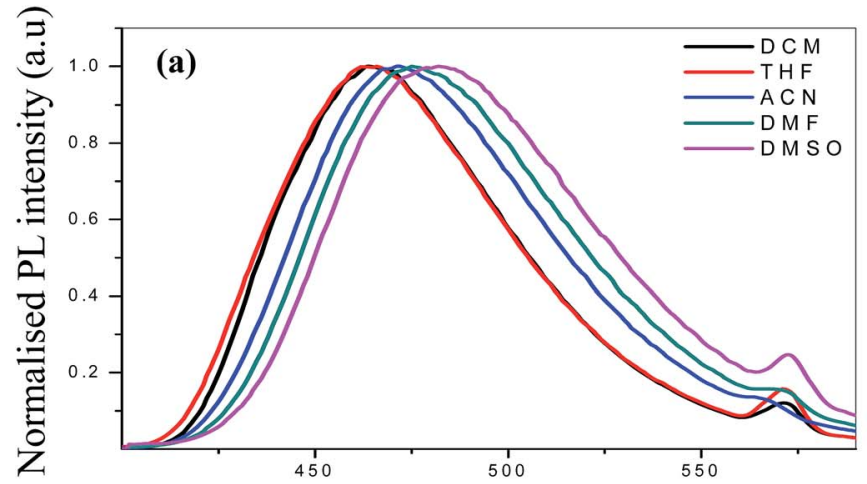

Wavelength $(\mathrm{nm})$

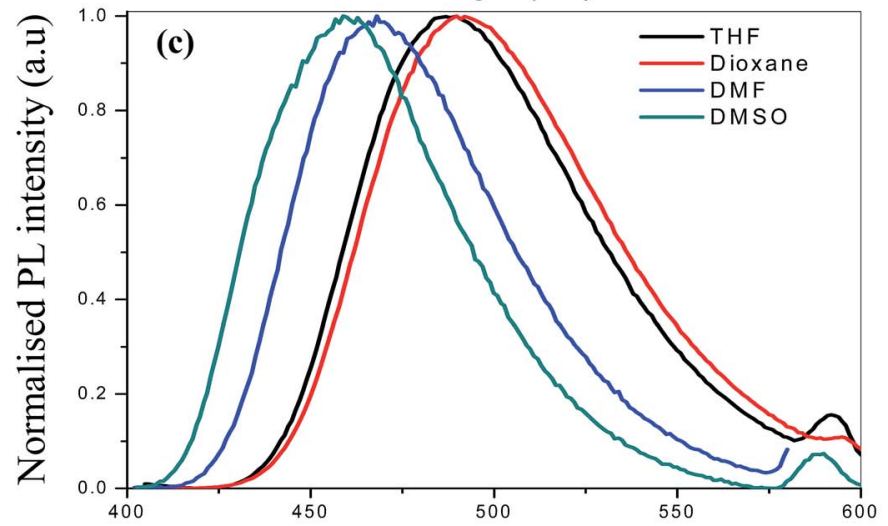

Wavelength $(\mathrm{nm})$
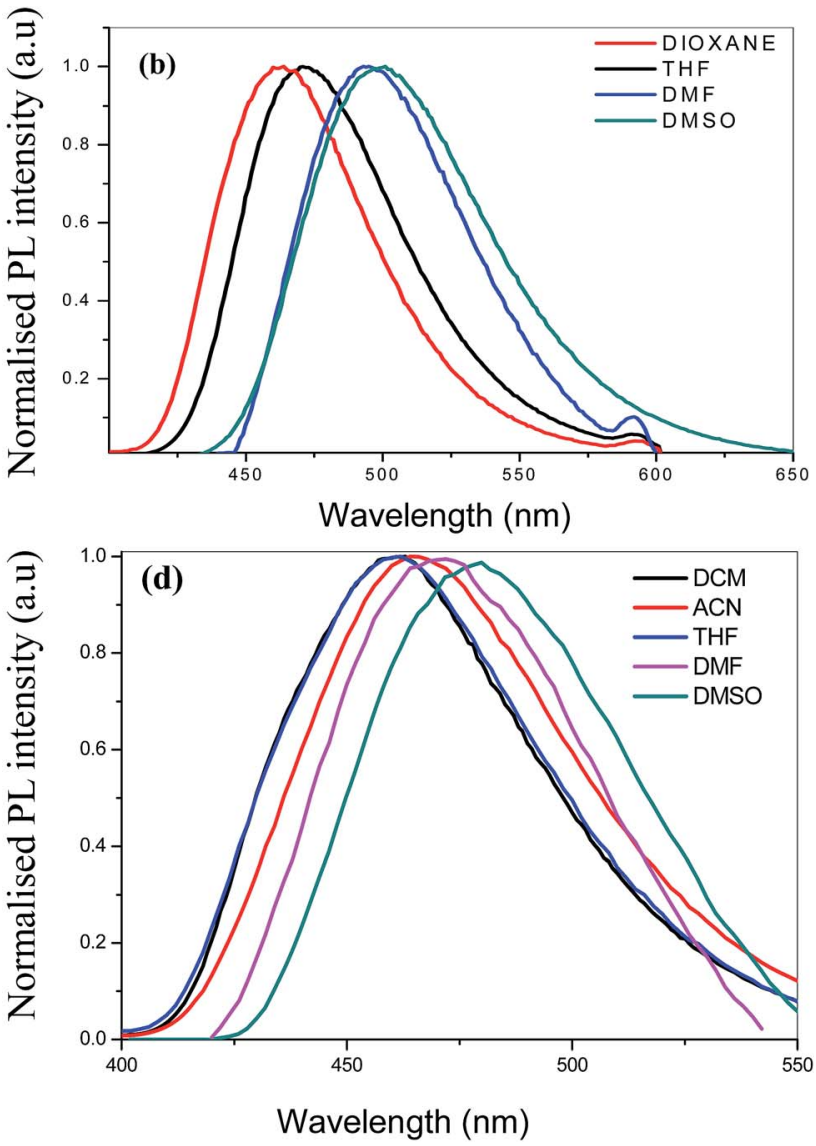

Fig. 3 Solvatochromic behavior of compounds. The effect of solvent polarity on the emission wavelength of compounds (a) 4, (b) 5, (c) 6 and (d) 8 . 
solution of compound $\mathbf{5}$, fluorescence intensity started to decrease and kept on decreasing for further increment in water content up to $90 \%$ (Fig. 4) which concluded that 5 do not possess AEE characteristics. In contrast, for compound $\mathbf{8}$ it was observed that fluorescence intensity started to increase from the beginning with the addition of $20 \%$ water only and increased until the water content reached $80 \%$ with a continuous red shift in emission intensity, which can be ascribed to the continuous increase in polarity of solution and the change in the morphology of the aggregates formed or crystallization enhanced emission might be occurring. ${ }^{36,39,40}$ The concentration of the THF-water system was maintained at $5 \mu \mathrm{M}$ always. The fluorescence quantum yield exhibited an enhancement from 0.06 to 0.2. However, when the content of water was further increased to $90 \%$, the fluorescence decreased rapidly, but did not quench fully. The reason could be the formation of agglomerates of solute molecules in a random way to form less emissive amorphous particles or the $\pi-\pi^{*}$ stacking in nanoaggregates which can also lead to the lowering of fluorescence. ${ }^{41}$ Similar results were observed for $\mathbf{1 1}$ and $\mathbf{1 2}$ (Fig. 4). Thus we expect that introduction of alkyl functionality into the coumarin structure contribute significantly to the enhanced solid state emission and make the coumarins good candidates for doped OLED devices.

\section{Molecular packing}

The crystal structure analysis provides the most direct evidence to understand the aggregation enhanced emission (AEE) mechanism in the solid state. We have successfully obtained two single crystals ( 5 and $\mathbf{8}$, Fig. 5) from a DMF-water mixture and a THF solvent, respectively, that could be promising evidence towards understanding the mechanisms in the solid state. The two crystals have common contorted geometries and adopt a twist-like conformation of the $2 H$-benzo[ $h]$ chromen-2one cores and phenyl moieties with torsion angles of $54.74^{\circ}$ and $51.55^{\circ}$ for 5 and angles of $58.15^{\circ}$ and $55.45^{\circ}$ for 8 . The crystal structure of 5 belongs to an orthorhombic system containing the $P 2_{1} 2_{1} 2$ space group with an interplanar angle between two planes of $55.45^{\circ}$ (Fig. S13 $\dagger$ ). As shown in the Fig. 5c, in each layer, naphthalene aromatic rings are in one plane and a hydroxyl $(-\mathrm{OH})$ group is chelated with the $-\mathrm{C}=\mathrm{O}$ oxygen of the lactone moiety through intermolecular $\mathrm{O}-\mathrm{H} \cdots \mathrm{O}\left(\mathrm{O}_{1}-\mathrm{H} \cdots \mathrm{O}_{3}\right.$, $2.821 \AA$ ) interactions, which could open non-radiative pathways for deactivation processes. In addition, the other supramolecular weak interactions e.g. $\mathrm{C}-\mathrm{H} \cdots \mathrm{O},\left(\mathrm{C}_{18}-\mathrm{H} \cdots \mathrm{O}_{1}, 3.421 \AA \mathrm{C}_{15}-\right.$ $\left.\mathrm{H} \cdots \mathrm{O}_{1}, 3.328 \AA\right)$ and $\mathrm{C}-\mathrm{H} \cdots \mathrm{N}\left(\mathrm{C}_{16}-\mathrm{H} \cdots \mathrm{N}_{1}, 3.508 \AA, \mathrm{C}_{19}-\mathrm{H} \cdots \mathrm{N}_{1}\right.$, $3.596 \AA, \mathrm{C}_{8}-\mathrm{H} \cdots \mathrm{N}_{1}, 3.337 \AA$ ) also play an essential role in building the zigzag network. Layers A-B and C-D layers are closely packed with partially overlapping benzo[ $h]$ chromen-2one polyaromatic cores through $\pi-\pi$ stacking $\left(\pi_{\text {average }}-\pi_{\text {average }}\right.$, $3.24 \AA)$ interactions to form the slipped parallel structure (Fig. 5e). Layers B and C are oriented in such a way that their aromatic rings are not interacting with each other. Therefore, we can conclude that intermolecular H-bonding, strong $\pi-\pi$ stacking contact, and other supramolecular interactions play key roles in quenching the PL signal of 5 in the solid state. ${ }^{42}$ On the other hand, the crystal structure of $\mathbf{8}$ belonging to the orthorhombic $\mathrm{Pca}_{2}$ space group with an interplanar angle of $61.14^{\circ}$ showed a zigzag pattern of the molecules in the crystal (Fig. 5d). It can be noted that substituting the hydroxyl group with an acetyl group removed intermolecular $\mathrm{H}$-bonding and increased the interlayer distance from $3.24 \AA$ to $3.70 \AA$. Furthermore, the $\pi-\pi$ interaction reduced between adjacent layers and thus simultaneously increasing the fluorescence intensity. ${ }^{36}$ In addition, weak interactions e.g. $\mathrm{C}-\mathrm{H} \cdots \mathrm{O},\left(\mathrm{C}_{3}-\mathrm{H} \cdots\right.$ $\left.\mathrm{O}_{2}, 3.445 \AA, \mathrm{C}_{12}-\mathrm{H} \cdots \mathrm{O}_{3}, 3.2425 \AA\right), \mathrm{C}-\mathrm{H} \cdots \mathrm{N}, \mathrm{C}_{2}-\mathrm{H} \cdots \mathrm{N}_{1}, 3.381 \AA$ and the cofacial $\pi-\pi$ stacking $\left(\pi_{\text {average }}-\pi_{\text {average }}, 3.705 \AA\right)$ (Fig. $5 f$ ) between adjacent layers were observed, but these interactions may favor the formation of an excimer which can give rise to new emissions in the PL spectra.

This supposition is supported by the origin of a new long range emission in the PL. As supported by these observations, one can expect similar behavior in the EL of devices.

\section{Thermal properties and HOMO-LUMO levels}

Utilizing the results of solid state fluorescence, structurally related compounds $5, \mathbf{8}, \mathbf{1 1}, \mathbf{1 2}, 16$ and 17 were selected for
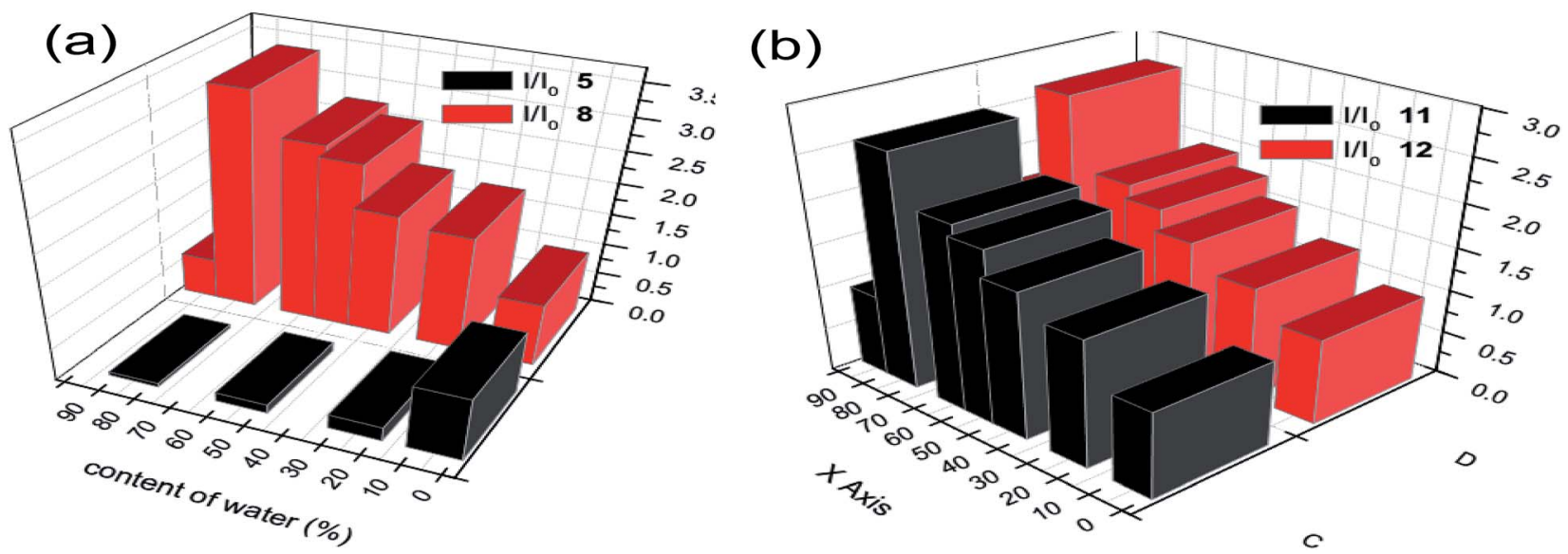

Fig. 4 (a) Comparison of the PL intensity change on the increasing water content in the THF-water system for $5 \mu \mathrm{M}$ solution of (a) 5 and 8 and (b) 11 and 12 . 
(a)

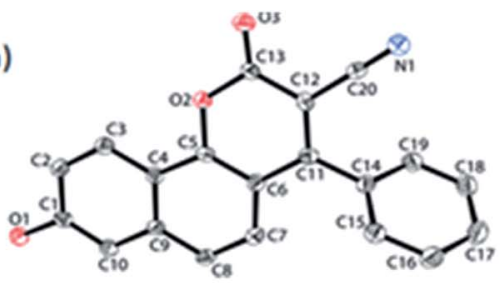

(c)

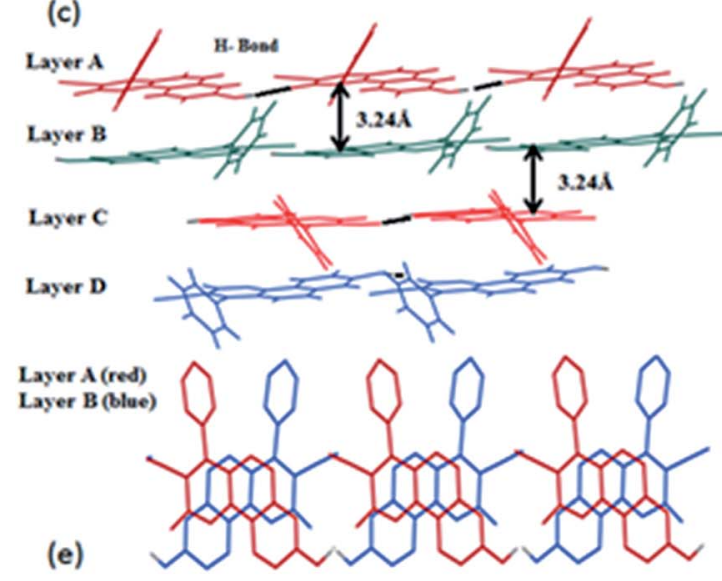

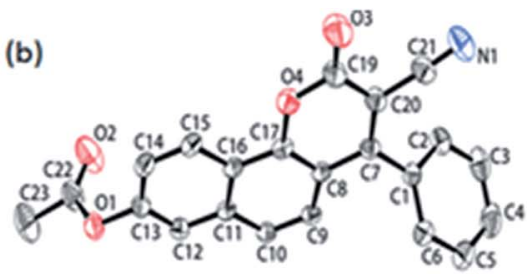

(d)

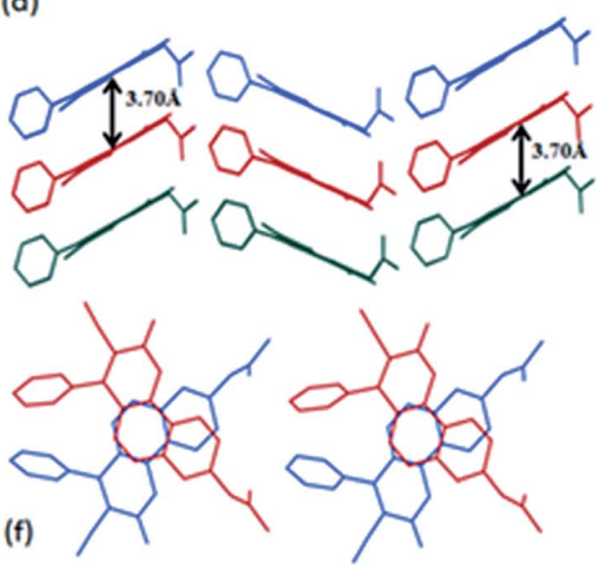

Fig. 5 Ortep diagrams of molecules (a) 5 and (b) 8. (c) Side view of the crystal lattice of 5 showing a hydrogen bond and short range contacts. (d) Side view of the crystal lattice of 8 showing a zigzag pattern and an interplanar distance. (e) Top view showing an overlap of aromatic rings between layer A and layer B in 5 . (f) Top view showing an interaction between adjacent layers of 8 .

further studies including device fabrication. Thermal behavior of these organic compounds was investigated by DSC and TGA (Fig. 6a). Parent compound 5 was found to be stable upto 300 ${ }^{\circ} \mathrm{C}$. Compound 8 exhibited a decomposition temperature $\left(T_{\mathrm{d}}=\right.$ 5\% weight loss) around $304{ }^{\circ} \mathrm{C}$ which is quite high, whereas 16 and 17 exhibited $T_{\mathrm{d}}$ around $261{ }^{\circ} \mathrm{C}$ and $268{ }^{\circ} \mathrm{C}$, respectively. Melting points were observed in the first heating scan of all the compounds without crystallization, which is expected to yield better stabilities of these fluorophores as electroluminescent materials. ${ }^{43}$ Solution electrochemistry studies were carried out to ascertain the redox behavior of these coumarin derivatives, and the results obtained were employed to evaluate the LUMO and the HOMO levels. All measurements were performed in a three electrode setup using $\mathrm{Ag} / \mathrm{AgCl}$ as a reference electrode and a Pt disc as a working electrode in acetonitrile for $\mathbf{8}$ and dichloromethane for $\mathbf{1 6}$ and 17, respectively. Ferrocene was used as the external standard. The LUMO for compound $\mathbf{8}$ was assessed at $-3.52 \mathrm{eV}$ from the onset reduction $\left(E_{\text {red }}\right)$, using the equation: $E_{\mathrm{LUMO}}=-\left(E_{\text {red }}+4.8\right) \mathrm{eV}$, where $E_{\text {red }}$ is the onset reduction potential relative to the $(\mathrm{Fc} / \mathrm{Fc}+)$ couple (Fig. $6 \mathrm{~b}){ }^{44}$ From the lowest energy absorption edge of the UV-vis absorption spectra in solution, the band gap $\left(E_{\mathrm{g}}\right)$ was calculated to be $2.88 \mathrm{eV}$, so $E_{\text {Hомо }}$ was assessed at $-6.40 \mathrm{eV}$. Similarly, onset reduction potentials for long chain ester derivatives $\mathbf{1 6}$ and $\mathbf{1 7}$ in their $\mathrm{CV}$ voltammograms were at $-0.98 \mathrm{~V}$ and $-1.00 \mathrm{~V}$, respectively. LUMO and HOMO energy levels for 16 and 17 were estimated to be lying at $-6.22 \mathrm{eV},-3.34 \mathrm{eV}$ and $-6.20 \mathrm{eV}$, and $-3.32 \mathrm{eV}$, respectively. Therefore long alkyl chains do not have noticeable influence on HOMO-LUMO energy levels unlike the effect on PL.

\section{Computational studies}

Density functional theory calculations have been carried out by employing the B3LYP ${ }^{45}$ hybrid functional and $6-311 \mathrm{G}(\mathrm{d}, \mathrm{p})$ basis set to understand the spectral properties and for the analysis of molecular orbitals. Gaussian 09 suite of programs is used for all calculations. ${ }^{46} \mathrm{~A}$ representative set of compounds comprising $\mathbf{5}$, 8, 11, 12 and 19 are used for the computational analysis. Optimized structures of compounds $\mathbf{5}$ and $\mathbf{8}$ along with their corresponding HOMO and LUMO are depicted in Fig. 7 (structure and frontier molecular orbitals of other compounds are given in Fig. S22 $\dagger$ ) and Table 1 summarizes the energy values of the HOMO, LUMO and band gap of all calculated compounds. The HOMO in both 5 and 8 are formed by the $\pi$-orbitals of the central ring system, lone pairs on oxygen atoms and the $\pi$-orbitals of carbonyl and cyanide groups and LUMO of both compounds are the corresponding $\pi^{*}$-orbitals. The phenyl group is nearly perpendicular to the plane of the naphthyl moiety in both compounds and is not contributing to the HOMO. The HOMO-LUMO energy gap in 5 is $3.59 \mathrm{eV}$ and the replacement of the -OH group by an ester group in $\mathbf{8}$ lowers the HOMO energy and increases the HOMO-LUMO energy gap to $3.66 \mathrm{eV}$ which explains the observed blue shift in the absorption wavelength. The computed LUMO energy and the HOMOLUMO energy gap in $\mathbf{8}$ is slightly different from the experimental values which is expected since the solvent effect and other possible interactions of $\mathbf{8}$ in the solvent is not included in the computation. The theoretical calculations that include the solvent effect [both Polarizable Continuum Model (PCM) and the conductor like polarizable continuum model (CPCM)] do 
(a)

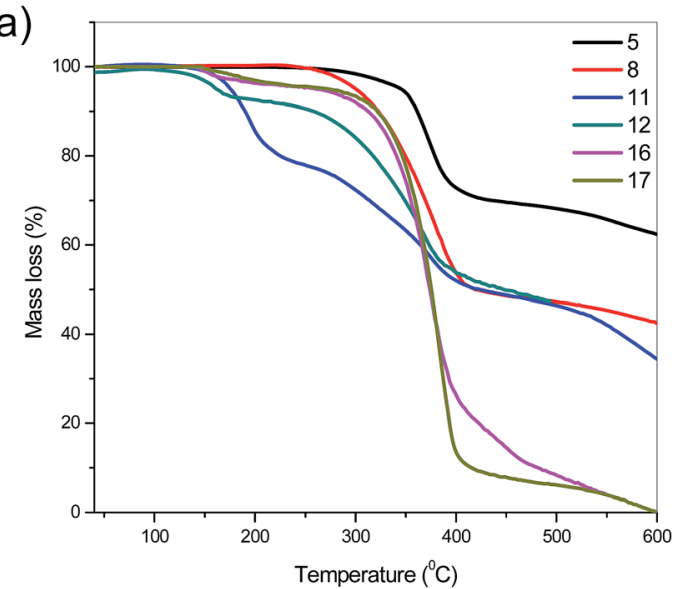

(b)

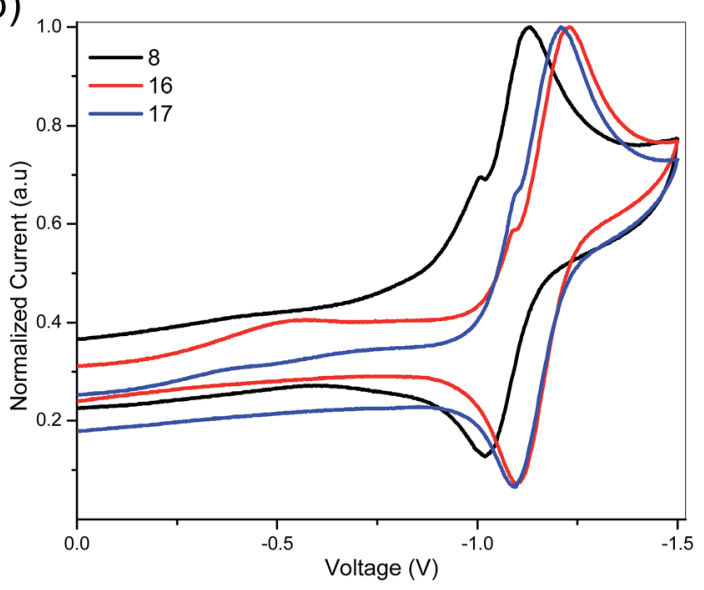

Fig. 6 (a) TGA graphs for selected compounds and (b) CV graphs for compounds 8,16 and 17 .

not make a significant change to the LUMO energy value (not greater than $0.1 \mathrm{eV}$ ). Therefore, the orbital energy values given in the text are calculated from gas phase calculations. The band gap of 8, 11, 12 and 19 are nearly the same showing that the length of the alkyl chain and even the replacement of the alkyl group by a phenyl group do not significantly change the HOMO-LUMO gap which can be rationalized from the fact that the substituents on ester carbonyl do not contribute to HOMO and LUMO in any of these systems and the inductive effect by the substituent on the naphthyl ring is almost negligible.

UV-vis absorption properties of all optimized compounds have been calculated at the TD-PBE0/6-311G(d,p) level of DFT. ${ }^{47}$ The solvent effect (THF) is treated with a conductor like polarizable continuum model (CPCM) implemented in Gaussian $09{ }^{48}$ The absorbance of all compounds are in the region of 240 $390 \mathrm{~nm}$ which are in good agreement with the experimentally recorded absorption profile (TD-DFT/CPCM spectra all compounds along with the molecular orbitals involved in electronic transition are given in the ESI, Fig. S23†). Peaks in the region of $380-390 \mathrm{~nm}$ are characterized by the $\pi-\pi^{*}$ (HOMO $\rightarrow$ LUMO) transition in all computed compounds while the absorption in 240-290 $\mathrm{nm}$ are resulted from the electronic transitions from HOMO and HOMO -1 to LUMO, LUMO + 1 and LUMO +2 , depending on the orbital energy and symmetry
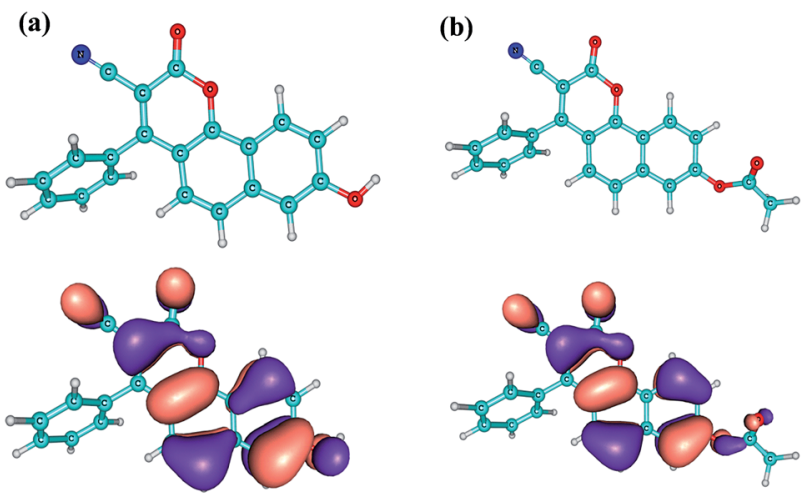

$\mathrm{HOMO}=-6.30 \mathrm{eV}$
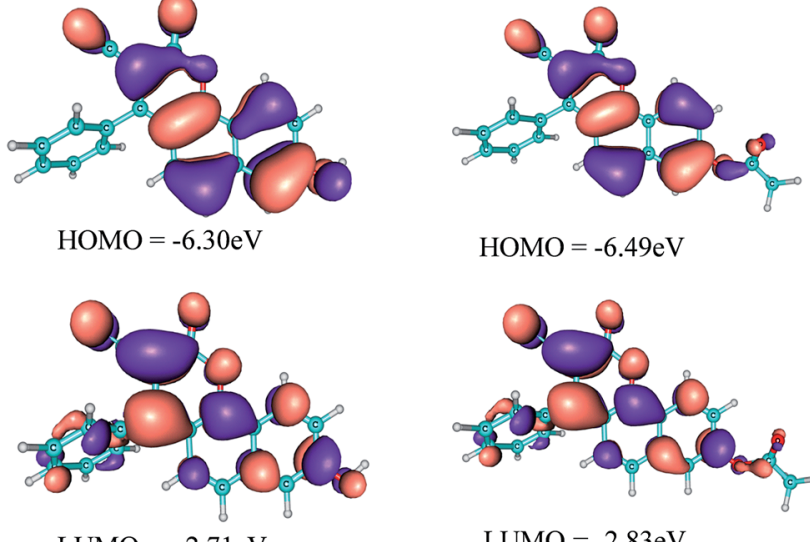

$\mathrm{HOMO}=-6.49 \mathrm{eV}$

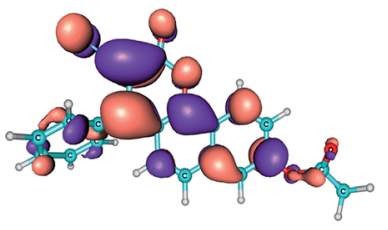

$\mathrm{LUMO}=-2.83 \mathrm{eV}$

Fig. 7 Theoretically calculated optimized geometries and frontier molecular orbitals. (a) Optimized structure and frontier molecular orbitals of 5. (b) Optimized structure and frontier molecular orbitals of 8 .

Table 1 Summary of molecular orbital calculations at the B3LYP/6$311 \mathrm{G}(\mathrm{d}, \mathrm{p})$ level and on cyclic voltammetry

\begin{tabular}{llll}
\hline Compound & $E_{\text {HОмо }}[\mathrm{eV}]$ & $E_{\text {LUMO }}[\mathrm{eV}]$ & $E_{\mathrm{g}}[\mathrm{eV}]$ \\
\hline $\mathbf{5}$ & $-6.30^{a}$ & $-2.71^{a}$ & $3.59^{a}$ \\
$\mathbf{8}$ & $-6.40^{b} /-6.49^{a}$ & $-3.52^{b} /-2.83^{a}$ & $2.88^{b} / 3.66^{a}$ \\
$\mathbf{1 1}$ & $-6.49^{a}$ & $-2.82^{a}$ & $3.67^{a}$ \\
$\mathbf{1 2}$ & $-6.47^{a}$ & $-2.81^{a}$ & $3.66^{a}$ \\
$\mathbf{1 6}$ & $-6.22^{b}$ & $-3.34^{b}$ & $2.88^{c}$ \\
$\mathbf{1 7}$ & $-6.20^{b}$ & $-3.32^{b}$ & $2.88^{c}$ \\
$\mathbf{1 9}$ & $-6.47^{a}$ & $-2.82^{a}$ & $3.65^{a}$
\end{tabular}

${ }^{a}$ B3LYP/6-311G(d,p) level. ${ }^{b}$ Using cyclic voltammetry. ${ }^{c}$ Band gap calculated from edge of the absorption profile.

$\left(\mathrm{ESI}^{\dagger}\right)$. The HOMO-LUMO energy gap (PBE0/6-311G(d,p)$\mathrm{CPCM}$ ) in 5 is $3.84 \mathrm{eV}$ and the replacement of the $-\mathrm{OH}$ group by an ester group in $\mathbf{8}$ lowers the HOMO energy and increases the HOMO-LUMO energy gap to $3.93 \mathrm{eV}$ which explains the observed blue shift in the absorption wavelength for the $\pi-\pi^{*}$ transition.

\section{Electroluminescent devices}

Based upon the PL behavior of coumarin derivatives 8, 11-18 in the solid state, coumarins 8, 11, 12, 16 and 17 were selected to investigate the change in their electroluminescence behavior as these selected compounds differ only in the chain length of ester functionality. After fabrication of the devices, the EL spectrum (Fig. 8a) and current-voltage-luminescence $(J-V-L)$ characteristics (ESI, Fig. S14-S21 $\dagger$ ) were recorded and simultaneously current and power efficiencies (ESI, Fig. S14-S21†) were 
also calculated for all devices. Since the PL spectrum of 8 covered a wide range of the visible region, Device 1: ITO/ $\alpha$-NPD $(30 \mathrm{~nm}) / \mathrm{EML}(35 \mathrm{~nm}) / \mathrm{BCP}(6 \mathrm{~nm}) / \mathrm{Alq} 3(28 \mathrm{~nm}) / \mathrm{LiF}(1 \mathrm{~nm}) / \mathrm{Al}$ $(150 \mathrm{~nm})$ was fabricated utilizing 8 as an emissive layer (EML). $\alpha$-NPD was used as the hole transport layer (HTL), BCP as the hole blocking layer (HBL) and $\mathrm{Alq}_{3}$ served as the electron transport layer (ETL). Electroluminescence (EL) spectra obtained were completely different from that obtained for the thin film (Fig. 8a). A completely new emission peak centered at $668 \mathrm{~nm}$ appeared in EL which did not appear in PL spectra either in solutions or in the solid state. It is to be noted that EL characteristics are sometimes affected by chemical and physical interaction at organic/organic interfaces in OLEDs. An interaction of organic materials at the interface forms a charge-transfer excited state complex, known as the exciplex. ${ }^{2,49}$ Hence, this could be probably due to the interaction of the dye (compound 8) with the $\alpha$-NPD or the BCP. Since BCP does not have its own emission, it simply restricts the passage of holes towards the ETL reducing the interaction of the EML with the ETL. Thus, it is assumed that there is an interaction between EML and $\alpha-\mathrm{NPD}^{50}$ resulting in exciplex formation thereby generating anomalous EL. To verify the presence of exciplex formation, PL spectra of the thin film of pristine $\alpha$-NPD and its mixture with dye derivative 8 were recorded (Fig. 8c).

From the data it was deduced that pristine $\alpha$-NPD and coumarin derivative $\mathbf{8}$ do not possess long range emissions in their thin film forms. However, a mixture of both shows the presence of long range (low energy) emissions justifying the exciplex formation in Device 1. This coumarin derivative 8 was than doped in s-CBP (host matrix) as the guest emitting material. To have the better emission properties, the doping concentration of the guest emitting material 8 was optimized utilizing different percentages of dyes $(0.5 \%, 1 \%, 1.5 \%, 2 \%$, and $3 \%$ ) in the host matrix. It was observed that $1 \%$ (by weight) of the compound revealed excellent performance with enhanced emission (Fig. 8e).${ }^{51}$ So, $1 \%$ of 8 doped in s-CBP was used as the EML and Device 2 was fabricated with configuration: ITO $/ \alpha$ NPD (30 nm)/s-CBP: 1\% 8 (35 nm)/BCP (6 nm)/Alq3 (28 nm)/LiF $(1 \mathrm{~nm}) / \mathrm{Al}(150 \mathrm{~nm})$ (Fig. 8d). Here, EL and PL spectra were almost similar (Fig. 8b), though, EL was much broader than PL and as expected it covered an almost whole visible spectrum resulting in white emission. The absence of host emission in

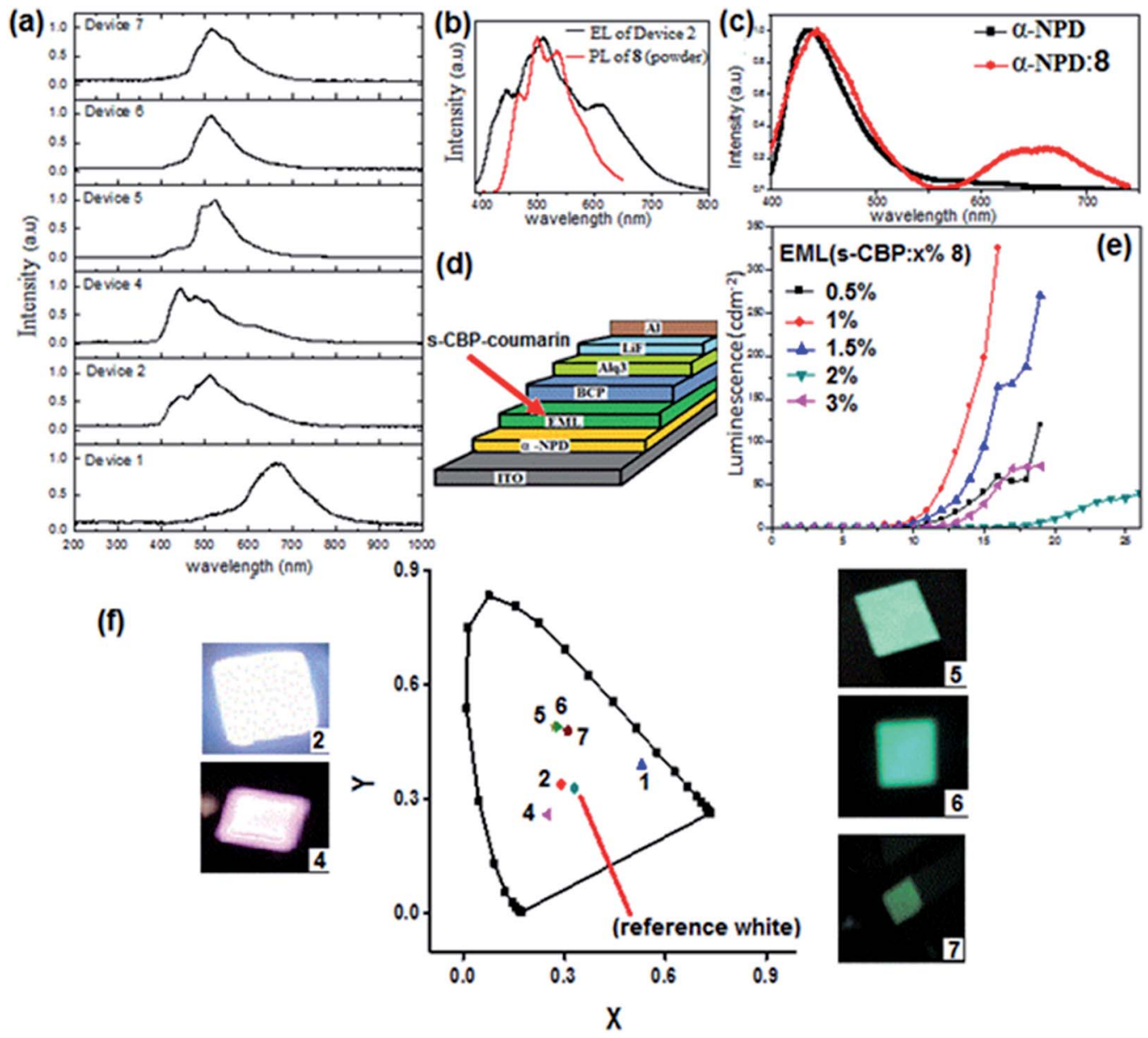

Fig. 8 (a) EL spectra of Devices 1, 2, 4, 5, 6, and 7. (b) Comparison of PL spectra of compound 8 in the solid state with EL spectra of Device 2 having (S-CBP: $1 \% 8$ ) as the EML. (c) Comparison of PL spectra of pure thin films of $\alpha$-NPD and premixed $\alpha$-NPD- 8 mixture. (d) Schematic representation of the device used for study. (e) Luminance characteristics for devices having $0.5 \%, 1 \%, 1.5 \%, 2 \%$, and $3 \%$ of dye doped on host s-CBP. (f) CIE diagram for devices with device pictures. 
electroluminescence confirmed the full energy transfer from the host to the guest dye in the s-CBP: coumarin device. The turn-on voltage for the device was observed to be 5-6 V. According to the Commision Internationale de L'Eclairage (CIE), Device 2 resulted in white-light emission with color coordinates $(0.29,0.34)$. To verify that emission originates from an organic compound only and no interference come from Alq3, Device $3[$ ITO/ $\alpha$-NPD $(30 \mathrm{~nm}) / \mathrm{s}-\mathrm{CBP}: 1 \% 8(35 \mathrm{~nm}) / \mathrm{PBD}(28 \mathrm{~nm}) /$ $\mathrm{LiF}(1 \mathrm{~nm}) / \mathrm{Al}(150 \mathrm{~nm})]$ was fabricated by replacing BCP and the ETL layer (Alq3) of Device 2 with 2-(4-biphenyl)-5-(4-tert-butylphenyl)-1,3,4-oxadiazole (PBD). EL obtained (Fig. S25 $\dagger$ ) was similar to that obtained from Device 2 which confirmed that no emission originated from the Alq3 layer. Thus the configuration of Device 2 was selected for further device fabrications. Devices 4, 5, 6 and 7 were fabricated utilizing 1\% of 11, 12, 16 and 17, respectively, as EML doped in S-CBP and their EL spectra were recorded (Fig. 8a). As expected, Device $4\left(V_{\text {on }}=10 \mathrm{~V}\right)$ showed white emission with violet tinges (CIE: 0.25, 0.26). But Device $5\left(V_{\text {on }}=7 \mathrm{~V}\right)$, Device $6\left(V_{\text {on }}=6 \mathrm{~V}\right)$ and Device 7 gave EL shifted towards bluish-green/greenish emissions with CIE: $(0.27,0.49)$, $(0.28,0.49)$ and $(0.31,0.48)$, respectively (Fig. $8 f)$. Thus it was observed that the alkyl chain length is playing an important role in tuning the electroluminescence of non-optimized device structures. The deep lying HOMO level of the guest with respect to the HOMO level of the host is possibly responsible for low carrier transport and carrier recombination ${ }^{52}$ and hence relatively low efficiencies of devices studied are observed. A better choice of the electron transport layer, hole transport layer and suitable host having energy levels matching with that of the host are expected to increase the device performance and reduce the turn on voltages. However, the present devices are found to be stable up to $18-20 \mathrm{~V}$.

\section{Conclusions}

In summary, a careful structure-emission relationship study led us to develop a small chemical library of fifteen novel hybrid coumarin derivatives and compound $\mathbf{8}$ was found to have application as an emissive material for WOLEDs. All these compounds were synthesized following a simple three-step procedure and tedious purification techniques such as column chromatography have been avoided to obtain the pure product. The photoluminescence of newly developed coumarin based compounds in solution and solid state was studied and a device with $1 \%$ of 8 in the s-CBP host gave white light emission utilizing a small alkyl substituent. Simultaneously color tuning by controlling intermolecular interactions in the solid state, which in turn was controlled by systematic functionalization with alkyl chains have been investigated. Single crystal structure studies helped us to understand the photoluminescence of these coumarins in the solid state which is different from the solution state. Utilizing these intermolecular interactions as the source of new intermolecular emitting species with single compound emission, for the first time, coumarin has been utilized as the sole emitting compound in WOLED devices. The use of a single emitting component and a simple synthesis procedure reduce the overall device fabrication cost as compared to those where multiple layers have been utilized for white light generation. The work to find optimized layers (HTL, ETL and host) for OLED devices for these series of novel coumarin dyes is in progress.

\section{Acknowledgements}

Financial support was received from the Department of Science and Technology, India (Grant no. SERB/F/2408/2012-13 and SR/ FT/CS-57/2010(G)). We are thankful to the Director, IIT Mandi for research facilities. The support of sophisticated instrument facility of Advanced Materials Research Center (AMRC), IIT Mandi, is thankfully acknowledged. SK greatly acknowledges University Grant Commission for providing doctoral fellowship. We warmly thank Prof. J.A. Gareth Williams for his valuable suggestions which helped us in improving the manuscript contents. We acknowledge the help of Pankaj Gaur and Anshul Sharma of IIT Mandi for their help during the manuscript preparation. One of the author (PS) thanks Department of Science and Technology (DST) for financial aid.

\section{References}

1 R. H. Jordan, A. Dodabalapur, M. Strukelj and T. M. Miller, Appl. Phys. Lett., 1996, 68, 1192-1194.

2 A. Kumar, R. Srivastava, S. S. Bawa, D. Singh, K. Singh, G. Chauhan, I. Singh and M. N. Kamalasanan, J. Lumin., 2010, 130, 1516-1520.

3 D. Thirion, M. Romain, J. Rault-Berthelot and C. Poriel, J. Mater. Chem., 2012, 22, 7149-7157.

4 S. Tao, Y. Zhou, C.-S. Lee, S.-T. Lee, D. Huang and X. Zhang, J. Mater. Chem., 2008, 18, 3981-3984.

5 P. Coppo, M. Duati, V. N. Kozhevnikov, J. W. Hofstraat and L. De Cola, Angew. Chem., Int. Ed., 2005, 44, 1806-1810; A. Poloek, C.-T. Chen and C.-T. Chen, J. Mater. Chem. C, 2014, 2, 1376-1380.

6 M. Mazzeo, V. Vitale, F. Della Sala, M. Anni, G. Barbarella, L. Favaretto, G. Sotgiu, R. Cingolani and G. Gigli, Adv. Mater., 2005, 17, 34-39.

7 R. S. Deshpande, V. Bulovic and S. R. Forrest, Appl. Phys. Lett., 1999, 75, 888-890; S. Chen, Q. Wu, M. Kong, X. Zhao, Z. Yu, P. Jia and W. Huang, J. Mater. Chem. C, 2013, 1, 3508-3524.

8 C. H. Kim and J. Shinar, Appl. Phys. Lett., 2002, 80, 22012203; S. Chen, G. Tan, W.-Y. Wong and H.-S. Kwok, Adv. Funct. Mater., 2011, 21, 3785-3793.

9 Y. Yang, M. Lowry, C. M. Schowalter, S. O. Fakayode, J. O. Escobedo, X. Xu, H. Zhang, T. J. Jensen, F. R. Fronczek, I. M. Warner and R. M. Strongin, J. Am. Chem. Soc., 2006, 128, 14081-14092.

10 G.-L. Law, K.-L. Wong, H.-L. Tam, K.-W. Cheah and W.-T. Wong, Inorg. Chem., 2009, 48, 10492-10494.

11 Y. S. Huang, J. H. Jou, W. K. Weng and J. M. Liu, Appl. Phys. Lett., 2002, 80, 2782-2784.

12 M. Anni, G. Gigli, V. Paladini, R. Cingolani, G. Barbarella, L. Favaretto, G. Sotgiu and M. Zambianchi, Appl. Phys. Lett., 2000, 77, 2458-2460. 
13 J. Kalinowski, M. Cocchi, D. Virgili, V. Fattori and J. A. G. Williams, Adv. Mater., 2007, 19, 4000-4005.

14 G. He, D. Guo, C. He, X. Zhang, X. Zhao and C. Duan, Angew. Chem., Int. Ed., 2009, 48, 6132-6135.

15 B. Pan, B. Wang, Y. Wang, P. Xu, L. Wang, J. Chen and D. Ma, J. Mater. Chem. C, 2014, 2, 2466-2469; B. Zhang, G. Tan, C.-S. Lam, B. Yao, C.-L. Ho, L. Liu, Z. Xie, W.-Y. Wong, J. Ding and L. Wang, Adv. Mater., 2012, 24, 1873-1877.

16 S. H. Kim, S. Park, J. E. Kwon and S. Y. Park, Adv. Funct. Mater., 2011, 21, 644-651.

17 A. Kumar Satpati, M. Kumbhakar, D. Kumar Maity and H. Pal, Chem. Phys. Lett., 2005, 407, 114-118.

18 M.-T. Lee, C.-K. Yen, W.-P. Yang, H.-H. Chen, C.-H. Liao, C.-H. Tsai and C. H. Chen, Org. Lett., 2004, 6, 1241-1244.

19 S.-Y. Park, M. Ebihara, Y. Kubota, K. Funabiki and M. Matsui, Dyes Pigm., 2009, 82, 258-267.

20 S. A. Swanson, G. M. Wallraff, J. P. Chen, W. Zhang, L. D. Bozano, K. R. Carter, J. R. Salem, R. Villa and J. C. Scott, Chem. Mater., 2003, 15, 2305-2312.

21 C.-T. Chen, C.-L. Chiang, Y.-C. Lin, L.-H. Chan, C.-H. Huang, Z.-W. Tsai and C.-T. Chen, Org. Lett., 2003, 5, 1261-1264.

22 C. W. Tang, S. A. Vanslyke and C. H. Chen, J. Appl. Phys., 1989, 65, 3610-3616.

23 T. Gensch, J. Hofkens, A. Heirmann, K. Tsuda, W. Verheijen, T. Vosch, T. Christ, T. Basché, K. Müllen and F. C. De Schryver, Angew. Chem., Int. Ed., 1999, 38, 3752-3756.

24 Y. Liu, M. Nishiura, Y. Wang and Z. Hou, J. Am. Chem. Soc., 2006, 128, 5592-5593.

25 V. K. Rai, M. Nishiura, M. Takimoto and Z. Hou, J. Mater. Chem. C, 2014, 2, 5317-5326; S. Varughese, J. Mater. Chem. C, 2014, 2, 3499-3516.

26 H.-P. Zhao, X.-T. Tao, P. Wang, Y. Ren, J.-X. Yang, Y.-X. Yan, C.-X. Yuan, H.-J. Liu, D.-C. Zou and M.-H. Jiang, Org. Electron., 2007, 8, 673-682; Y.-H. Yu, C.-H. Huang, J.-M. Yeh and P.-T. Huang, Org. Electron., 2011, 12, 694-702.

27 M. J. Jurow, B. A. Hageman, E. DiMasi, C.-Y. Nam, C. Pabon, C. T. Black and C. M. Drain, J. Mater. Chem. A, 2013, 1, 15571565; Y. Hua, S. Chang, D. Huang, X. Zhou, X. Zhu, J. Zhao, T. Chen, W.-Y. Wong and W.-K. Wong, Chem. Mater., 2013, 25, 2146-2153.

28 H. B. Akkerman, S. C. B. Mannsfeld, A. P. Kaushik, E. Verploegen, L. Burnier, A. P. Zoombelt, J. D. Saathoff, S. Hong, S. Atahan-Evrenk, X. Liu, A. Aspuru-Guzik, M. F. Toney, P. Clancy and Z. Bao, J. Am. Chem. Soc., 2013, 135, 11006-11014.

29 J. E. Anthony, S. Subramanian, S. R. Parkin, S. K. Park and T. N. Jackson, J. Mater. Chem., 2009, 19, 7984-7989.

30 P. Kumar, K. N. Shivananda, W. Zajączkowski, W. Pisula, Y. Eichen and N. Tessler, Adv. Funct. Mater., 2014, 24, 2530-2536; A. M. Della Pelle, P. J. Homnick, Y. Bae, P. M. Lahti and S. Thayumanavan, J. Phys. Chem. C, 2014, 118, 1793-1799.

31 S. E.-D. N. A. F. Mohamed Abd El Aziz Ez-Taweel, A. Ghani Ali Elagamey and S. Zaki Ahmed Sowellim, in Anales de qui'mica, 1995, pp. 589-593.
32 B. Lu, J. Xu, Y. Li, C. Liu, R. Yue and X. Sun, Electrochim. Acta, 2010, 55, 2391-2397.

33 J. N. Moorthy, P. Venkatakrishnan, P. Natarajan, D.-F. Huang and T. J. Chow, J. Am. Chem. Soc., 2008, 130, 17320-17333.

34 J. Kalinowski, G. Giro, M. Cocchi, V. Fattori and P. Di Marco, Appl. Phys. Lett., 2000, 76, 2352-2354.

35 B. Carlotti, R. Flamini, I. Kikaš, U. Mazzucato and A. Spalletti, Chem. Phys., 2012, 407, 9-19.

36 Y. Kubota, S. Tanaka, K. Funabiki and M. Matsui, Org. Lett., 2012, 14, 4682-4685.

37 P. Bourbon, Q. Peng, G. Ferraudi, C. Stauffacher, O. Wiest and P. Helquist, J. Org. Chem., 2012, 77, 2756-2762.

38 G. Mu, W. Zhang, P. Xu, H. Wang, Y. Wang, L. Wang, S. Zhuang and X. Zhu, J. Phys. Chem. C, 2014, 118, 86108616.

39 C. Shi, Z. Guo, Y. Yan, S. Zhu, Y. Xie, Y. S. Zhao, W. Zhu and H. Tian, ACS Appl. Mater. Interfaces, 2012, 5, 192-198.

40 Z. Zhao, S. Chen, X. Shen, F. Mahtab, Y. Yu, P. Lu, J. W. Y. Lam, H. S. Kwok and B. Z. Tang, Chem. Commun., 2010, 46, 686-688.

41 E. Pusztai, I. S. Toulokhonova, N. Temple, H. Albright, U. I. Zakai, S. Guo, I. A. Guzei, R. Hu and R. West, Organometallics, 2013, 32, 2529-2535.

42 X. Feng, B. Tong, J. Shen, J. Shi, T. Han, L. Chen, J. Zhi, P. Lu, Y. Ma and Y. Dong, J. Phys. Chem. B, 2010, 114, 16731-16736.

43 Z. Yang, Z. Chi, T. Yu, X. Zhang, M. Chen, B. Xu, S. Liu, Y. Zhang and J. Xu, J. Mater. Chem., 2009, 19, 5541-5546.

44 A. Goel, V. Kumar, S. P. Singh, A. Sharma, S. Prakash, C. Singh and R. S. Anand, J. Mater. Chem., 2012, 22, 1488014888.

45 (a) A. D. Becke, J. Chem. Phys., 1993, 98, 5648-5652; (b) C. Lee, W. Yang and R. G. Parr, Phys. Rev. B: Condens. Matter Mater. Phys., 1988, 37, 785-789.

46 M. J. Frisch, et al., Gaussian 09, Gaussian Inc., Wallingford, 2010.

47 C. Adamo and V. Barone, J. Chem. Phys., 1999, 110, 61586169.

48 (a) V. Barone and M. Cossi, J. Phys. Chem. A, 1998, 102, 19952001; (b) M. Cossi, N. Rega, G. Scalmani and V. Barone, J. Comput. Chem., 2003, 24, 669-681.

49 B. R. Kaafarani, A. A. O. El-Ballouli, R. Trattnig, A. Fonari, S. Sax, B. Wex, C. Risko, R. S. Khnayzer, S. Barlow, D. Patra, T. V. Timofeeva, E. J. W. List, J.-L. Bredas and S. R. Marder, J. Mater. Chem. C, 2013, 1, 1638-1650.

50 Y. Zhao, T. Yu, Y. Wu, H. Zhang, D. Fan, Z. Gan, L. Yang, X. Han and Y. Zhang, J. Fluoresc., 2012, 22, 631-638; N. Matsumoto and C. Adachi, J. Phys. Chem. C, 2010, 114, 4652; N. Matsumoto, M. Nishiyama and C. Adachi, J. Phys. Chem. C, 2008, 112, 7735-7741.

51 J. Chen and D. Ma, J. Appl. Phys., 2004, 95, 5778.

52 A. Benor, S.-Y. Takizawa, C. Pérez-Bolivar and P. Anzenbacher, Appl. Phys. Lett., 2010, 96, 243310. 